\title{
Organizational Creativity Management: Discussion Elements
}

\author{
Gestão da Criatividade Organizacional: Elementos de Discussão
}

Universidade Federal de Pernambuco, Centro de Ciências Sociais Aplicadas, Departamento de Ciências Administrativas, Recife, PE, Brasil ${ }^{1}$ 


\title{
Resumo
}

Este artigo propõe trabalhar com o conceito teórico de gestão da criatividade ao promover uma reflexão demarcada por incentivar relações de trabalho que envolvam indivíduos criativos e lideranças criativas em atitudes que fomentem uma cultura criativa. Tal análise considera a criatividade como um precursor da inovação e avalia-a como capaz de melhorar a competitividade organizacional, haja vista que, aqui, criatividade é entendida como um fenômeno social. A discussão aborda condições e características relacionadas ao indivíduo, à liderança e à cultura. O gerenciamento da criatividade é o componente de uma grade gerencial voltado para interferir em contextos internos e externos da organização ao rever práticas desviantes e divergentes ao estimulo de seus processos criativos. O desenvolvimento da criatividade ao longo do tempo é ilustrado por um conceito chamado de espiral da criatividade. Em conclusão, analisar a criatividade como algo que é produzido coletivamente e tem elementos gerenciáveis aumenta a capacidade de tomar decisões que estimulam a criatividade, permitindo que esta seja gerenciada no nível coletivo.

Palavras-chave: criatividade; gestão organizacional; indivíduo; liderança; cultura.

\begin{abstract}
This article proposes to work with the theoretical concept of creativity management by promoting a reflection defined by encouraging work relationships that involve creative individuals and creative leadership in attitudes that foster a creative culture. This analysis considers creativity as a precursor of innovation and evaluates it as a universe capable of improving organizational competitiveness, since, creativity is understood as a social phenomenon. The discussion in this article addresses conditions and characteristics related to the individual, to leadership and culture. Creativity management is a component of a managerial grid focused on interfering in the internal and external contexts of an organization by reviewing deviant and divergent practices regarding the stimulation of creative processes. The development of creativity over time is illustrated by a concept called the spiral of creativity. In conclusion, analyzing creativity as something that is collectively produced and has manageable elements increases the ability to make decisions that foster creativity and allow it to be managed collectively.
\end{abstract}

Keywords: creativity; organizational management; individual; leadership; culture.

JEL Codes: O3, M1, D23. 


\section{Introduction}

The aim of this article is to develop and analyze a theoretical concept regarding creativity management at the micro level. The line of argument is developed to elucidate the strategic relationship among three basic elements associated with creativity management in the organizational sphere: the individual in his or her collective context, the organizational culture and the leadership process.

This article contributes to reflections about labor relations policies that enable the participation of individuals in practices aimed at generating innovation in companies and encourage leaders to have open attitudes toward the development of an organizational culture that fosters creativity.

Previous empirical studies have demonstrated the importance of considering the relationship between creativity and dynamic innovation processes (Caniëls, Stobbeleir, \& Clippelee, 2014; ElerudTryde \& Hooge, 2014; Muzzio, 2017). In this sense, the implementation of creativity management is key to the discussion and enhances the leverage of organizational creativity that brings structural projects to the conceptual status of innovation.

The development of the central theoretical concept begins with two basic principles of creativity. The first is that creativity in an organizational context can be seen as a manageable phenomenon, given that it is made up of professionals, rules, procedures and resources, all of which can be shaped by an organization's goals and policies (Amabile, 1997). The second principle is that creativity in an organizational context is a social phenomenon formed by the interactions among three elements: the first element is the individual, a professional with the skills needed to generate ideas; the second element is leadership, which strategically promotes actions that foster creativity; and the last element is culture, which provides the symbolic support necessary for a social cohesion around creativity.

Creativity management increases organizational creativity and enhances innovation through management practices that integrate individual skill, leadership orientation, and cultural symbolism, thereby allowing continuous growth of creative action through the creativity spiral. Our assumption is that individuals, leadership and culture, when managed using creative logic, are sufficient elements for enhancing organizational creativity. This assumption is plausible given the interrelationship between these elements, with creativity as a structuring axis. This interrelationship refers to the fact that creativity is enhanced by these articulated elements and feeds back into the system, allowing creativity to increase in an organization's individuals, leadership and culture. Thus, creative individuals can influence creative leadership and creative culture. In turn, creative leadership influences creative individuals and the consolidation of creative culture. At the same time, creative culture influences individuals and creative leadership.

This theoretical concept suggests that creativity management has the potential to promote the development of practices that foster collective creativity, and when organizations devote resources to the resulting innovative effort, the generation of ideas becomes something that can be actively managed. This view complements an individual dimension of creativity in which human agency exists (Eisenhardt, 1989). However, in the organizational context, this is not sufficient to consolidate institutional action that encourages the development of creative and innovative projects (Perry-Smith, 2006).

The theoretical understanding of the phenomenon of organizational creativity demonstrates its current relevance, as the field of creativity is still seen as lacking theories that constitute a lucid examination of this topic (Anderson, Potocnik, \& Zhou, 2014). In addition, understanding how creativity management occurs is justified by the scarcity of knowledge available in the field regarding the processes that support the generation of creative ideas (Berg, 2016). Moreover, analyses of the innovation process usually take a macro procedural perspective, meaning there is no well-established theoretical body of literature specifically concerned with debating creativity management (Caniëls, Stobbeleir, \& Clippelee, 2014). 
This concept indicates the existence of a new frontier of knowledge to broaden our understanding of the creative process. This contributes to expanding management capacity with respect to the efficiency of creative efforts to produce artifacts of symbolic value that precede the act of innovation itself. This concept differs from currently existing alternatives in terms of the emergence of the component of creativity and the reason why its three elements, analyzed together, imply a new perspective for managerial practice.

Understanding this new means of managing the creative process opens possibilities for expanding knowledge to spark debate between academics and managers regarding the topic of innovation (Damanpour, 1991). For academics, the importance of having a theoretical model that integrates creativity management with innovation derives from the fact that it organizes knowledge that sheds light on the explanation of how the phenomenon of creativity can be managed, highlighting its relationship with the organizational context. Regarding the contribution that the concept of creativity management makes to managers, the existence of a theoretical concept for this phenomenon means that this knowledge will be available to be applied in an organizational setting to contribute to managerial practice aiming to optimize the innovation process. This is because its applicability is considered plausible with regard to incremental or complex processes, such as the theoretical models that result from this study, which include the paradigms of open innovation, user innovation and innovation as a product of crowdsourcing (Barbaroux \& Attour, 2016; Dunne \& Dougherty, 2016).

The application of creativity management models has the potential to modify academic research and managerial practice, leading to a significant increase in creativity. These models promote a perspective of creativity as a trait that is neither merely subjective nor an isolated skill of an individual. Such models regard creativity as an organizational process that increases in efficacy if well managed. This efficacy lies in applying knowledge of the constituent elements of individuals, leadership and culture, which are available only in isolated forms, in an articulated model in which each element influences and is influenced by the other elements. This approach places creativity at a higher level of application that could not be achieved without using assumptions of creativity management.

The analytical framework developed here focuses on individuals, leadership and culture. Other factors influence the creative process, such as interpersonal relationships, which can influence collective creativity, and technology, which has the potential to affect creative processes. However, our analytical focus, although incomplete, provides sufficient elements to understand the idea generation process, due to the close relationship between these elements, since the leadership process only occurs with the involvement of individuals and is permeated by cultural aspects of an organization.

With respect to methodological procedures, this examination is a theoretical analysis. This article was developed using bibliographical research on theoretical and empirical studies in databases that, based on a systematic literature review, supported the arguments used in the construction of the concept of creativity management.

\section{Organizational Creativity}

Creativity is the process of creating ideas and entails the emergence of a new element capable of establishing new socio-economic standards, culminating in innovation (Amabile, 1997). In this sense, it is viewed as a phenomenon that precedes and shapes the innovation process (Caniëls et al., 2014). In accordance with the studies by Caniëls, Stobbeleir and Clippelee (2014) and Baer (2012), we consider creativity to be an independent process that precedes innovation, although there is a relationship between these two concepts, with creativity being linked to idea generation and innovation being related to the commercial application of such ideas. Creativity is also considered a phenomenon that occurs on two levels, the first of which is the individual level. The second level, which is the focus of this discussion, lies in the social sphere. 
From the simple generation of ideas to the concept of complex undertakings, the creative process has been expanding its scope in recent years to include a view of collective creativity shaped by social networks that are able to increase innovation in an organic and rhizomatic realm of organizational interactions (Héraud, 2016). In this sense, organizations establish new roles, systems and processes to actively engender, support and manage creative activities to be transformed into innovative products (Bergendahl \& Magnusson, 2015; Elerud-Tryde \& Hooge, 2014; Harrison \& Rouse, 2015).

Creativity is understood here as a social process (Perry-Smith \& Shalley, 2003), in that it is a set of actions connecting people with the creation of innovative products and services (Dunne \& Dougherty, 2016), subject to the influence of socio-political dynamics that occur between interest groups. Creativity is viewed as occurring in accordance with the use of legitimation procedures by actors, governed by shared conventions that provide a collective meaning (Patriotta \& Hirsch, 2016). Perry-Smith and Shalley (2003) claim that the work environment influences the strength of creative practice through the results of group interaction, an opinion also held by Carnabuci and Diószegi (2015). In addition, Mainemelis (2010) argues in favor of creativity guided by social standards that lay the groundwork for its consolidation, even providing for the possibility that creativity may result from behavior that deviates from this standard.

During its phase of getting buy-in among peers, creativity needs to overcome the current social legitimacy by achieving greater efficiency or exploiting additional gains that derive from the implementation of this new idea, which may be thwarted by the interests of existing groups or coalitions, which would mean blocking a potentially innovative initiative.

Creativity is closely related to innovation. From a management perspective, understanding innovation is defined by understanding the factors (such as availability of resources or margin for error) that inhibit or facilitate its development. This perspective can be extrapolated to the process of creativity. In this sense, the manager's role is to understand the means by which different organizational forces and the relationships among them facilitate or hinder creativity.

The organizational forces that influence the creative ability of teams can vary throughout the creative process. In light of this, Caniëls et al. (2014) argue that creativity goes through three stages: idea generation, idea promotion and idea implementation. Management may have a different role to play in each of these stages, such as employing a transformational leadership style in the initial stage of the process or transactional leadership in its final stage.

Organizational creativity is also associated with a multidisciplinary perspective, involving the skills of multi-functional company teams from different fields of knowledge who work together and complement each other to generate new perspectives on solving problems and generating innovative projects (Patriotta \& Hirsch, 2016; Vissers \& Dankbaar, 2002). Therefore, this environment that socially enhances creativity exposes individuals to a diversity of perspectives that, in combination, generate a creative scope structured by an organizational network that allows social capital to take the dynamics of sharable actions to the level of innovation (Carnabuci \& Diószegi, 2015).

\section{Elements of Creativity and the Managerial Grid}

The structural elements of creativity management are the individual, leadership and culture. It is appropriate to discuss how they are configured in the concept presented. To do so, we have developed a managerial grid, illustrated in Figure 1, that presents different configurations of managerial practice. The use of this schematic helps analyze the combination of elements being discussed and distinguish them in situations to which creativity management is not applicable. Thus, the analytical perspectives of these three elements are shown to be useful to leverage the subsequent development of the theoretical concept of creativity management. The managerial grid reflects combinations of possibilities in two dimensions, the first of which concerns the relationship of organizational practices (called managerial 
view), which has to do with the degree to which the organization is willing to change its organizational values, processes and procedures: change $x$ maintenance. The second concerns the predominant source of influence for change in the organizations processes, procedures and practices (termed managerial direction): internal $x$ external. These combinations generate a 2 x 2 matrix with four management types: bureaucratic management, adaptation management, change management and creativity management. Within each of these types of management, there are configurations of the three elements associated with organizational management.

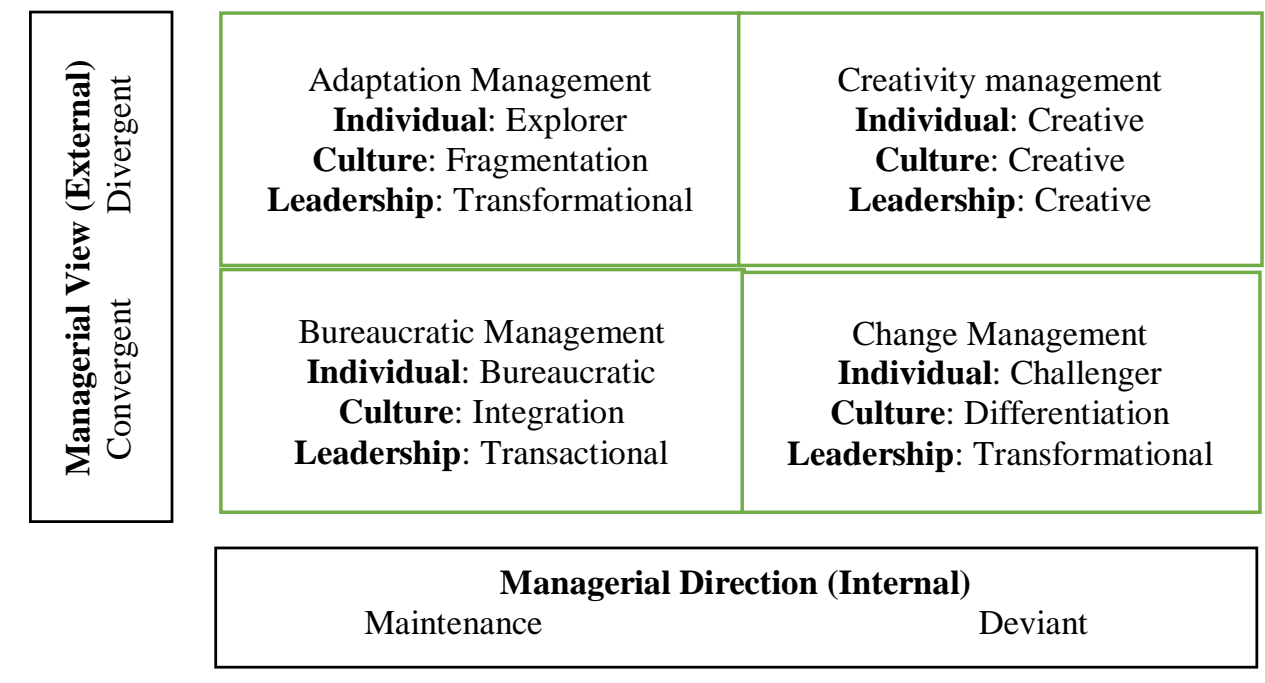

Figure 1. Managerial Grid

The dimension managerial view concerns to what extent a management style is consistent with the externally established status quo, that is, with some manner of operating in the market. It is based on two strata: convergent and divergent. Thus, convergent thought corresponds to maintenance of the status quo and canonical assumptions of the field and the established mainstream, as observed by DiMaggio and Powell (1983). Divergent thought, in contrast, relies on positions that challenge the established core and accepted conventions (Montanari, Scapolan, \& Gianecchini, 2016; Patriotta \& Hirsch, 2016).

The dimension managerial direction is anchored in two perspectives, maintenance and deviant, which differ in terms of whether managerial practices are aimed at maintaining or modifying the current management model, associated with the organizational standards. The maintenance perspective implies continuity of the existing managerial pattern of strict adherence to established norms and values, whereas the deviant perspective permits behavior that challenges established norms and values (Bass, 1990; Mainemelis, 2010). Thus, the management types discussed above are based on the practical configuration of the three organizational elements already highlighted.

\section{The individual in the collective context}

Within the organizational space, the individual seen through the collective lens is immersed in a social web that involves his or her behavior, performance, personal and professional relationships. Regarding creativity, the individual's insights about the dynamics of inventiveness are channeled and reordered based on collective concepts that influence the individual's actions and make them significant to the implementation of innovative ideas (Perry-Smith \& Shalley, 2003). This also occurs because the interaction of talented individuals and creative communities plays a key role in innovative production. In addition to being mechanisms of pure knowledge, such interactions are recognized as learning processes that highlight successful technological skills in the exchange of knowledge (Héraud, 2016).

The individual's stance with regard to the establishment can vary from dutiful agreement to outright defiance. Adaptive or innovative individuals have an environment that is or is not conducive to 
their work styles, applicable to different types of organizational arrangements (Chua, Roth, \& Lemoine, 2015).

\section{Organizational culture}

The second element of the concept is the culture, which involves a set of beliefs and values of a particular social group, transmitted symbolically through rituals, rites, stories and tales of heroes that lend behavioral cohesion to this group, while also setting it apart from other social groups (Chua et al., 2015; Smircich, 1983).

Martin (1992) considers organizational culture a fluid and heterogeneous condition. According to this author, culture is considered integrated when there is a homogeneous perspective of the whole and alignment throughout the group. It is also possible for culture to be understood as a differentiated dimension; in this case, the group is composed of subgroups that share views in a micro context, while they also share some macrostructural bonds that give them cohesion under certain conditions. Finally, culture can be understood as fragmented, being experienced in a diffuse context of ephemeral coalitions and constant divisions, while some common guiding elements persist.

These different possible views of the cultural sphere do not undermine the idea that rules are common to all these conceptual types and constitute mechanisms of influence that affect social behavior. In stricter cultural environments, norms guide the consolidation of homogeneity, whereas in more permissive cultural spaces, there is a greater acceptance of deviation from the norms, and such behaviors affect collective creativity.

\section{Organizational leadership}

The third element of this discussion is leadership, a classic theme in the organizational literature. There is a long-standing division regarding this topic between transactional and transformational leadership. Transactional leadership is based on transactions between leaders and followers, who are rewarded or punished based on their performance, grounded in a vision of leadership that prescribes rigid controls of conformance (Bass, 1990).

Transformational leadership occurs when the leaders expand and elevate the interests of their followers, generate awareness and acceptance of the group's purpose and mission and encourage the team to look out for the group's interest. This leadership type is marked by charisma, intellectual stimulation and individual consideration (Bass, 1990). This leadership style is characterized by articulation of an inspiring vision, promoting change by acting as a coach (Caniëls et al., 2014).

Transformational leaders employ charisma, individual consideration, inspirational motivation and intellectual stimulation, seeking to transform their followers' personal values and urge them to higher levels of action at which, by being empowered, they achieve greater creativity (Gumusluoglu \& Ilsev, 2009).

\section{Types of management}

Three types of management presented in the managerial grid will be analyzed briefly here because this article focuses on creativity; consequently, a specific section will be devoted to discussing creativity management, which is the theoretical concept developed here.

According to the managerial grid presented, bureaucratic management is the intersection between the convergent managerial view and the maintenance practice. From an external viewpoint, this means that the manager seeks to conform to the established mainstream. Internally, the manager aims for stability and to keep the seemingly satisfactory current state of affairs in the long term, running like a mechanistic organization. Burns and Stalker (1961) classify mechanistic organizations as hierarchical and highly structured, with well-defined formal roles and accessible communication in which 
information tends to flow vertically. This type of management is consistent with a model in which the individual is of the bureaucratic type, the culture is integration (Martin, 1992), and leadership is transactional (Bass, 1990).

Adaptation management is produced by the intersection between a maintenance managerial direction and a divergent managerial view. Internally, the manager works to replicate the established precepts and values through the use of management techniques that promote stability (Burns \& Stalker, 1961). Externally, the institutional forces of change (DiMaggio \& Powell, 1983) can influence management decisions, leading these managers to adapt to market changes. The prevailing organizational conditions promote the explorer individual who is alert to environmental changes, but who lacks the space and autonomy to take action internally. This context is consistent with a fluid scenario in which the culture of fragmentation enables the existence of diffuse and ephemeral groups (Martin, 1992), who at times are more susceptible to external change forces and at other times are more inclined to internal stability. Regarding leadership, a transformational symbolic space prevails (Bass, 1990).

Change management occurs as a result of the intersection of the convergent managerial view with deviant managerial direction. Internally, there is openness to a position that deviates from the established norms, but this is accompanied by an external action of convergence with the established institutional forces, limiting the internal dynamic. There is room in this quadrant for the individual who challenges and criticizes established values. There is more room here for a culture of differentiation (Martin, 1992), which makes a conceptual distinction between well-defined groups, in this case, some who favor external stability and others more focused on maintaining the prevailing internal order. The transformational leadership style predominates (Bass, 1990), in which the leader encourages autonomy in the followers, though still aligned with the canonical assumptions of the field.

\section{Creativity Management}

This type of management results from the intersection of the divergent managerial view and the deviant managerial direction, in a context that requires an intense creativity to boost innovation. Here, the organizational conditions converge with the creative individual, creative culture and creative leadership style (Muzzio, 2017).

Internally, the infringement of organizational norms occurs through deviant behavior, an irreverent attitude that can damage social relationships but may prove a fruitful source of creativity that contributes to corporate competitiveness.

Mainemelis (2010) defines deviant behavior as a breach of management orders to work on a new idea, which occurs at the individual level. In the author's view, this behavior does not seek to violate the overall cultural objectives but rather to achieve them in a different manner.

Externally, Berg (2016) maintains that creativity and innovation occur when creative people operate under a perspective of divergence from the established status quo. This process usually involves a search for new associations, combinations or perspectives. Paradoxically, in contrast, managers should adopt a convergent position related to a certain concern with its commercial applicability, economic feasibility and track record of achievements, trying to minimize the risk associated with innovation. Therein lies the challenge for creative leadership to stimulate the new, but without losing sight of the market, compatible with the complex perspective that creativity entails (Rickards \& Moger, 2000).

Next, the discussion turns to the specific roles played by the individual, leadership and culture in managing creativity. 


\section{The creative individual}

In an organization, the individual becomes part of a collective context governed by institutional rules that end up driving the social process through legitimation. From a creative perspective, this individual ends up having to disseminate his or her initial insights, with creativity turning into innovation only after making its way through legitimation processes and power games to secure the resources needed to consolidate the original idea, which is further modified by the ideas and knowledge of third parties on the path to the final version of the product or process.

According to Parjanen (2012), a creative individual has certain skills that enable him or her to analyze a question from multiple perspectives and take a critical stance regarding established reality, facilitating the emergence of creativity. This individual is the primary source of creativity, and, as with innovation, it would be inappropriate simply to boost the creative quotient of each individual in the expectation that this would make a significant difference, as creativity requires a conducive organizational context to occur.

According to Mietzner and Kamprath (2013), this individual has skills that need to be convergent with the environment of creativity. This is related to the ability to modify one's behavior and knowledge base, taking into account the ties between individual and social competence. According to the authors, this individual must keep an open mind to novelties and have a dynamic knowledge about the interdisciplinary nature of the creative field.

With respect to integration with the other examined elements, because creative action can generate tension with established values, this individual skill of having one's creative ideas legitimized is linked to one's ability to read organizational culture and to act as much as possible in accordance with institutionalized values and rules. Similarly, an individual must have the ability to successfully convince leadership by demonstrating the pertinence of his or her novel idea because this capability will allow the individual to spread the new creative idea and promote its application.

\section{Creative leadership}

The creative leader must provide a climate and work environment conducive to creativity through motivational, affective and cognitive mechanisms (Byron \& Khazanchi, 2015). According to Rickards and Moger (2000), these types of leaders modify the scope and the level of the team's performance through benign structures composed of the following seven factors that foster cooperation:

1. platform of understanding - respecting other members' points of view, sharing vision, knowledge and values, and facilitating the development of new ideas;

2. shared vision - members share a sense of purpose and responsibility for the team's progress;

3. climate - a positive work environment among members who exchange approaches that stimulate creativity;

4. resilience - the leader stresses the principle of making the team flexible to address frustrated expectations or difficulties;

5. idea owners - efforts to build ideas focused on those for which the entire team's commitment is seemingly achievable;

6. network activators - good communication with members outside the group through a network that harnesses skills,

7. knowledge and resources to solve the team's problems;

8. learning from experience - encouragement to learn on one's own, opportunities for growth, change, adaptation and creative problem-solving. 
According to the authors, the presence of these factors reduces or eliminates barriers that hinder the implementation of benign structures, thus favoring the emergence of collective creativity.

Creative leadership is marked by planning that focuses on the benefit of creativity, encouragement for the diversity of creative ability, good communication between the leader and followers, and competence to build a constructive method to leverage creativity (Amabile, 1997). From this perspective, creative leadership is based on both the generation and sharing of knowledge.

In an integrative perspective that incorporates the three examined elements, as someone who fosters creativity, a leader must recognize the rules, values and cultural rituals that facilitate the spread of new creative ideas with application potential and use them to enhance creativity. The leader should also encourage individuals to proactively behave in accordance with a creative perspective; in this manner, leaders can fulfill their role of leading processes that result in increased creativity.

\section{Creative culture}

As a defining element of organizational values, when a culture values a certain trait, the social relations and organizational practices, which focus on rules, regulations and standards, will be endowed with content that allows this trait to guide collective behavior. For example, placing a high value on creativity factors, such as the availability of time and resources, not only has an operational effect on the creative potential but also makes a symbolic statement that this creativity is important to the group.

According to Fairhurst (2009), the leader should articulate his or her vision through the strategic use of cultural artifacts such as slogans, symbols, rituals, ceremonies and stories of success or heroism. These symbolic elements have the ability to disseminate the desirable values and promote identification with the organization, and in this manner, leaders facilitate the emergence of a context guided by shareable values. In this sense, Chua, Roth and Lemoine (2015) argue that culture plays a fundamental role in enhancing creativity. In their view, even though culture generates a certain convergent thought, it can facilitate the idea selection process, given the need to legitimate them among peers in the organization.

Cultural elements influence creativity through the socialization process. A culture of creativity and innovation extends beyond the internal context of the business because the connections established among the various types of expertise can also occur in other organizations and agents through a network structure. In this case, too, the organizational culture places a high value on external relations and promotes an internal symbolic structure that fosters these connections and increases their effectiveness.

In terms of integration among the three examined elements, culture is a source and result of collective behavior that consolidates itself; however, culture is not a decision agent, a characteristic that is exclusive to individuals and leaders. Thus, these other two elements acting in convergence with cultural values is relevant because such actions facilitate the process of persuasion among peers and thereby promote the effective application of a creative idea. Over time, such behavior contributes to the consolidation of cultural values that facilitate creativity management, generating a virtuous cycle.

\section{Conceptual Discussion}

To better elucidate the conceptual discussion, let us restate the theoretical concept here: creativity management increases organizational creativity and enhances innovation through a management style that integrates individual skill, management guidelines and cultural symbolism, thus enabling continuous creative growth through the creativity spiral.

The effectiveness of creativity management consists in establishing organizational structures and positions that allow each element to be directed toward boosting creativity. Some organizational 
conditions favor and others hinder the efficiency of the individual, leadership and culture and the coordination of these elements to consolidate creative management.

\section{At the individual level}

Regarding the individual in his or her collective context, we emphasize the important role of actors who present ideas that do not conform to the existing organizational patterns, that is, who challenge the established logic of the status quo (DiMaggio \& Powell, 1983), thereby tapping into the creativity that leads to innovation. Such deviant behavior (Mainemelis, 2010) may be tolerated to the point that it increases creativity without fundamentally changing the existing structural-relational logic.

The individual embedded in his or her social context exhibits traits and attitudes that facilitate creativity, such as motivation, communication with peers, independence, readiness to learn, openness to change, persistence with his or her ideas, ability to give and receive critiques and confidence in others (Amabile, 1997; Mietzner \& Kamprath, 2013). Endowed with these traits, he or she is apt to promote the collective creative process, which goes through the collective conception of actors with diverse expertise who cooperate internally and externally, allowing new concepts to emerge that make it possible to break through the limits of knowledge (Nonaka \& Takeuchi, 1995; Parjanen, 2012).

\section{At the leadership level}

The leader has a prominent role because of his or her ability to guide the process by which symbolic value is produced and to influence an individual's behavior. Leadership promotes interactions with the aim of applying this creativity (Sohmen, 2015). For example, in an organizational network, creative leaders can identify the center and periphery of the structure and recognize that some peripheral actors may have creative talent but face difficulty legitimating their ideas because they lack a central position and familiarity with the dominant conventions (Patriotta \& Hirsch, 2016). In this sense, the creative leader tends to have the means to encourage teams such that the periphery and center of the structure operate in harmony, thereby allowing the flow of creative ideas from different actors in the core to leverage innovation.

This leader provides a supportive environment and encourages followers to develop their creative abilities. To this end, the leader's attitude requires certain traits that facilitate creativity. Among these are making time available for reflection about how to put the ideas generated into practice, challenging subordinates to develop their skills, expanding training in areas outside their specialization such that subordinates broaden their scope of knowledge, making material, financial and operational resources available to generate innovations, building physical and social environments for collective interaction and encouraging constructive feedback when errors in the creative process occur (Epstein, Kaminaka, Phan, \& Uda, 2013).

\section{At the cultural level}

Culture is the basis for the relationships established in a social group and plays a major role in the background and in the formation of a symbolic base to sustain everyday decisions in the organizational sphere, thus promoting the emergence of values that facilitate the creative process.

In general, creativity is anchored in specific cultural values, as their intangible elements constitute a body of tacit knowledge (Nonaka \& Takeuchi, 1995) that is not structurally transferable. In light of this, creativity management is associated with the effort to endow the social framework with values and symbols that support individuals' and leaders' actions, ensuring a certain legitimacy for actions that focus on producing and implementing ideas.

Creative culture is characterized by the high value placed on agile decision-making, tolerance for mistakes, conflict management, teamwork (Naranjo-Valencia \& Calderón-Hernández, 2015), 
encouraging divergent thinking (Mainemelis, 2010) and the generation of ideas and critical analysis focused on refining the creative process (Harvey \& Kou, 2013).

Coordination among the three elements and its link with creativity, establishing the theoretical concept of creativity management, is illustrated in Figure 2.
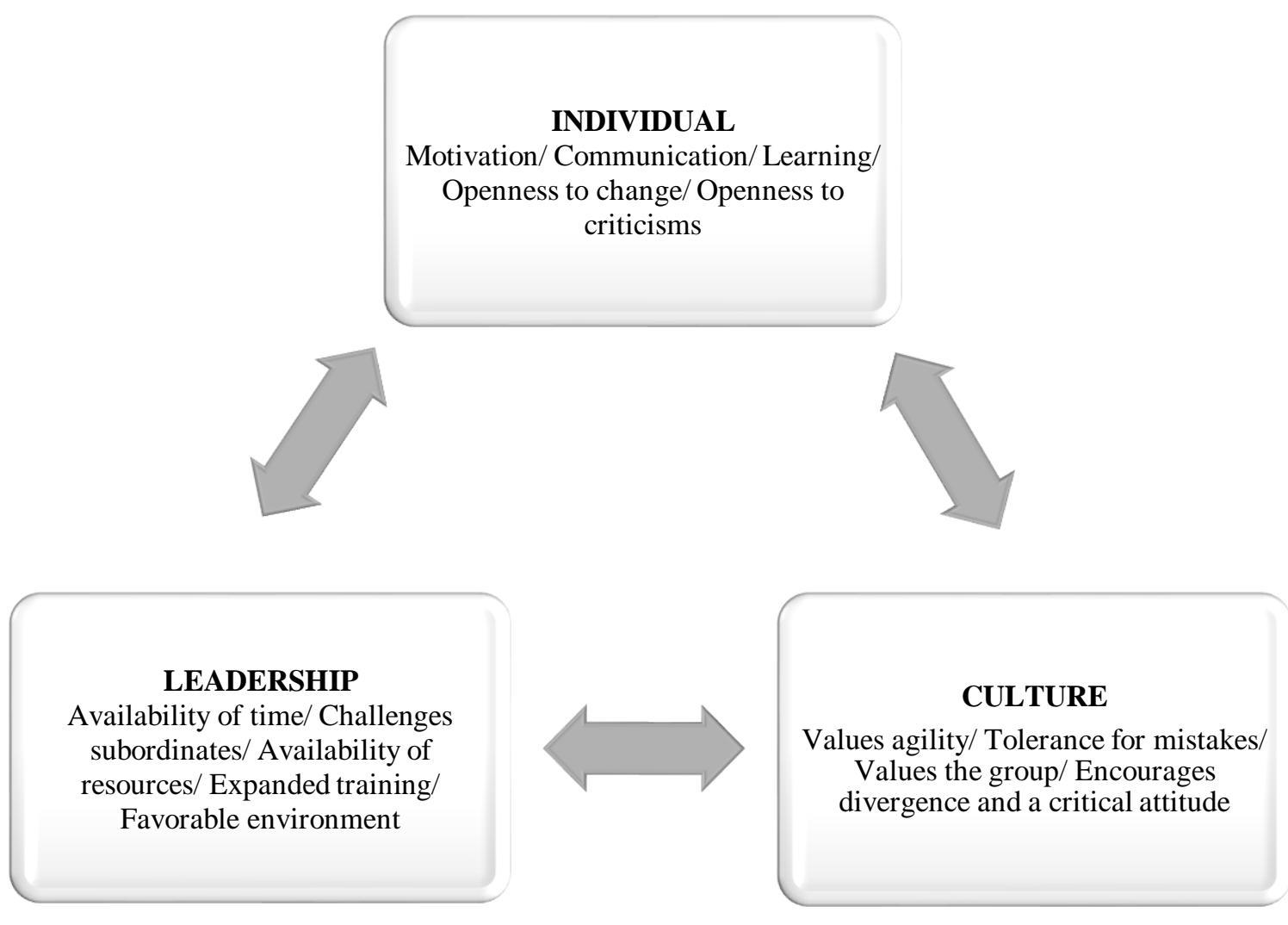

Figure 2. Theoretical Concept of Creativity Management

Figure 2 shows that since the three examined elements are interrelated, creativity is established as an axis of articulation among these elements. Thus, concurrently, creativity increases via this integration and promotes a feedback loop in the system; as a result, creativity also acts as an influencing factor for new levels of the described phenomenon for the three elements in a dynamic and continuous manner.

Each element exercises simultaneous and continuous influence over the others in a dual process, which is in agreement with Giddens (1984), who holds that the duality is based on the relationship among components of a social reality, in which each is fundamental to the constitution of the other and is, in turn, influenced by the other. For this author, action and structure are not independent but are instead constitutive of each other; that is, social structures are not only constituted by human agency but also the very means of this constitution.

In the context of creativity management, an individual influences the leadership process while being influenced by it. For example, a creative individual can be a disseminator of ideas that are accepted by leadership, which begins to disseminate such ideas to an entire group. In the same manner, this individual influences organizational culture and is simultaneously influenced by organizational culture. For instance, in the long term, the creative profile of an individual is incorporated by his or her peers and is eventually recognized as a value and disseminated as a cultural element. Finally, leadership is a factor that influences culture; concurrently, culture defines leadership. As an example, when leadership 
continuously adopts creativity-facilitating practices, creativity becomes recognized as a cultural value and therefore influences individuals in their daily actions.

Thus, distinct relations can be established:

- The individual with the skills and characteristics required for the creative process facilitates leadership's guidance due to the ability to implement the strategic guidelines established.

- The individual with the skills required for the creative process more easily incorporates the values of a creative culture because he or she already possesses the personal traits convergent with the culture.

- Creative leadership offers support in the form of resources and behaviors that facilitate greater efficiency in the individual's and group's creative effort.

- Creative leadership allows greater incorporation of the values of a creative culture by providing the group resources that consolidate the central symbolic role of creativity.

- The culture of creativity makes it easier for the individual to make sense of creativity by valuing symbolic conditions consistent with what is valued by this agent.

- The culture of creativity provides symbolic support to leaders who facilitate the spread of ideas and strategic directions anchored in a creative approach.

These relationships established among individual, leadership and culture act simultaneously as a mechanism for integration and aggregation of the material and symbolic conditions to make the organizational context more creative, constituting a virtuous circle. At this level, creativity is seen as a collective phenomenon that is consolidated only when there exists an appropriate level of structural, material and behavioral conditions acting together, providing individuals and leaders with the conditions and resources needed to generate creative ideas.

The inter-relationship of structural elements of creativity management is essential for the generation of ideas, given the social and policy perspective of the organization and the need for legitimation and complementary knowledge from individuals to consolidate ideas and transform them into products or services.

It is in this sense that action closely coordinated among the individual, leadership and culture focused on creativity becomes capable of boosting the generation of creative ideas and organizational innovation. This being the case, the application of creativity management has the potential to provide managers a mechanism that can help transform tacit knowledge into explicit knowledge, contributing to innovative, creative dynamism.

\section{The spiral of creativity management}

The manner in which the level of creativity develops over time is expressed in the form of a spiral. By considering the individual in the collective context, and leadership and culture as manageable elements, we argue that this management has the potential to continuously increase organizational creativity in a diagrammatic concept termed here the spiral of creativity management (Figure 3), following the concept of the knowledge spiral (Nonaka \& Takeuchi, 1995). 


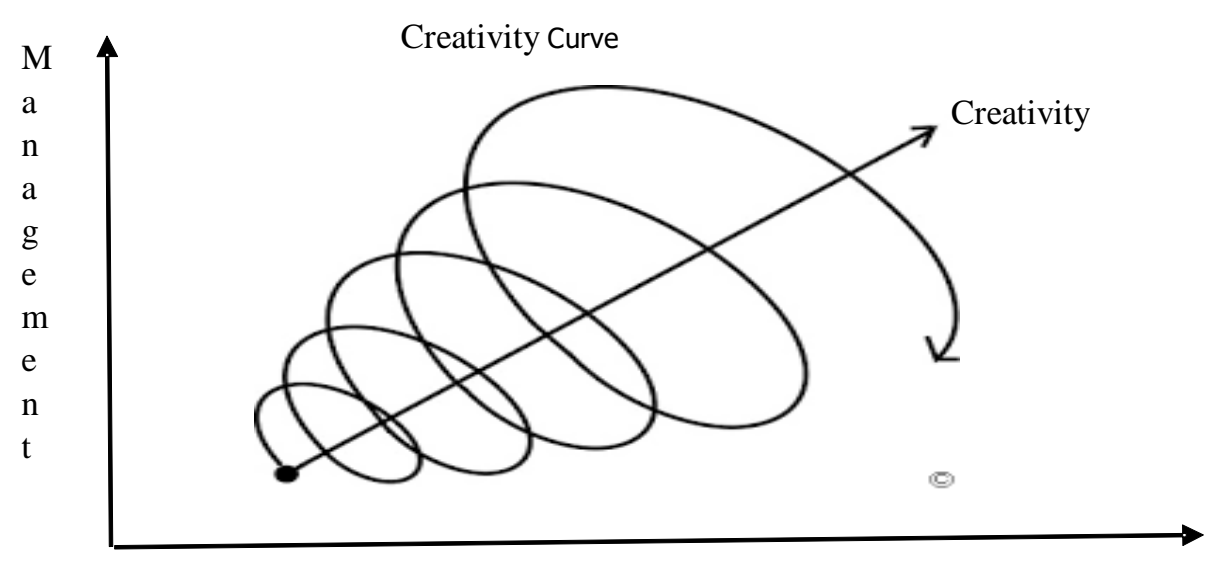

Time

Figure 3. Spiral of Creativity Management

Applied over time, creativity management results in a process of expanding collective creativity, which is conceptualized using the so-called creativity curve. The principle used here comes from Nonaka and Takeuchi (1995), marked by the logic of transforming tacit knowledge into explicit knowledge, embedded in a network of knowledge. Our model differs from those authors' model in its application to the context of creativity and its specification of the elements required for it to occur, in addition to the manner in which they interact to leverage collective creativity.

The spiral shape contains moments in which the creativity curve, despite its overall upward trajectory, is at a lower level. This is consistent with the view that creativity is a non-linear and ambiguous process (Harrison \& Rouse, 2015; Rickards \& Moger, 2006), that is, the level of creativity does not always grow in the short term. However, the accumulated collective expertise, together with the learning acquired in the previous cycle, has the ability to restart the creative process in a new production cycle. This spiral has periods in which the application of creativity is less intense due to the existence of periods in which innovation is incremental or more limited in scope, whereas at other times, disruptive innovations and more robust innovative changes prevail, meaning there are different levels of speed and direction in the creativity curve representing accelerated levels of the spiral of creativity management.

From this perspective, the more creativity management is applied over time, the greater the growth of organizational creativity, represented by the straight line in Figure 3 in the form of a vector, and the greater its potential for innovation.

To complement understanding of the theoretical concept, we present three observations that should be considered for the consolidation of creativity management. The first is that creativity management cannot occur without the presence of paradoxical conditions, in which one of the manager's roles is to tolerate apparent contradictions (Smith \& Lewis, 2011), which are common to the process of generating and implementing new ideas.

The second observation concerns the implementation process, which is consistent with shifts in the management types presented in the managerial grid, so that, for example, traditional management may turn into creative management. For this to happen, the characteristics of the individual, leadership and culture must change, which requires a period of time, especially regarding the cultural aspect, which is not prone to abrupt change (Smircich, 1983).

The third characteristic is its non-exclusive perspective. For example, bureaucratic organizations may also have a creative aspect and be able to develop innovation. Moreover, the fact that creativity management is not employed does not mean individuals and organizations operate without any 
management or control of their creative processes. What we are arguing for is creativity management's potential as a more efficient means to boost creativity and innovation through a conscious managerial strategy.

\section{Final Considerations}

This study has aimed to present the theoretical concept of creativity management, which brings together the individual in the collective context, the organization's leadership process and the organizational culture as an efficient means for expanding organizational creativity. The objective was met by defining the outline and the coordination of these three elements, thus making it possible to understand how managers can better manage the organization's creative process.

The implementation of this concept has the potential to modify management practice via the introduction of organizational attitudes and processes consistent with the characteristics and particular features of creative action focused on continuously increasing creativity.

The concept advances our knowledge by arguing that innovation can be boosted by introducing management of the creative process, which precedes innovation. Analyzing creativity as something that is collectively produced and has manageable elements increases the ability to make decisions that foster creativity by making it possible to manage it at the collective level.

We proposed a managerial grid that illustrates a typology of management styles based on distinct internal and external influences for changes to the organizational processes. One advance in knowledge focused on creativity management, where the discussion demonstrated how the elements boost creativity. Another contribution to the field is the discussion of the spiral of creativity management, which determines the manner in which creativity grows over time.

Future studies can make an ever greater contribution to the field by identifying potentially limiting conditions by introducing the variables time and/or space (Whetten, 1989). Future quantitative studies may provide new knowledge by comparing firms that use creativity management with others that employ one of the managerial grid's other management types. Qualitative analyses in the form of case studies may provide specific details about businesses that apply creativity management, which would only be possible through more in-depth research.

\section{Acknowledgements}

This work has received financial support by the National Council for Scientific and Technological Development (CNPq) of Brazil.

\section{Contributions}

$1^{\circ}$ and $2^{\circ}$ author: Both authors conceived of the presented idea and contributed to the final manuscript. 


\section{References}

Amabile, T. M. (1997). Motivating creativity in organizations: On doing what you love and loving what you do. California Management Review, 40(1), 39-58. https://doi.org/10.2307/41165921

Anderson, N., Potocnik, K., \& Zhou, J. (2014). Innovation and creativity in organizations: A state-ofthe science review and prospective commentary. Journal of Management, 40(5), 1297-1333. https://doi.org/10.1177/0149206314527128

Baer, M. (2012). Putting creativity to work: The implementation of creative ideas in organizations. Academy of Management Journal, 55(5), 1102-1119. https://doi.org/10.5465/amj.2009.0470

Barbaroux, P., \& Attour, A. (2016). Approches interactives de l'innovation et gestion des connaissances. Innovations, (49), 5-14. https://doi.org/10.3917/inno.049.0005

Bass, B. M. (1990). From transactional to transformational leadership: Learning to share the vision. Organizational Dynamics, 18(3), 19-31. https://doi.org/10.1016/0090-2616(90)90061-S

Berg, J. M. (2016). Balancing on the creative highwire: Forecasting the success of novel ideas in organizations. Administrative Science Quarterly, 61(3), 433-468. https://doi.org/10.1177/0001839216642211

Bergendahl, M., \& Magnusson, M. (2015). Creating ideas for innovation: Effects of organizational distance on knowledge creation processes. Creativity and Innovation Management, 24(1), 87101. https://doi.org/10.1111/caim.12097

Burns, T., \& Stalker, G. M. (1961). The management of innovation. London: Tavistock.

Byron, K., \& Khazanchi, S. (2015). Rewards' relationship to creativity, innovation, and entrepreneurship. In C. S. Shalley, M. A. Hitt, \& J. Zhou (Eds.), The Oxford handbook of creativity, innovation, and entrepreneurship (pp.47-59). New York, EUA: Oxford University Press.

Caniëls, M. C. J., Stobbeleir, K. de, \& Clippelee, I. de (2014). The antecedents of creativity revisited: A process perspective. Creativity and Innovation Management, 23(2), 96-110. https://doi.org/10.1111/caim.12051

Carnabuci, G., \& Diószegi, B. (2015). Social networks, cognitive style, and innovative performance: A contingency perspective. Academy of Management Journal, 58(3), 881-905. https://doi.org/10.5465/amj.2013.1042

Chua, R. Y. J., Roth, Y., \& Lemoine, J. (2015). The impact of culture on creativity: How cultural tightness and cultural distance affect global innovation crowdsourcing work. Administrative Science Quarterly, 60(2), 189-227. https://doi.org/10.1177/0001839214563595

Damanpour, F. (1991). Organizational innovation: A meta-analysis of effects of determinants and moderators. The Academy of Management Journal, 34(3), 555-590. https://doi.org/10.5465/256406

DiMaggio, P. J, \& Powell, W. W. (1983). The iron cage revisited: Institutional isomorphism and collective rationality in organizational fields. American Sociological Review, 48(2), 147-160. https://doi.org/10.2307/2095101

Dunne, D. D., \& Dougherty, D. (2016). Abductive reasoning: How innovators navigate in the labyrinth of complex product innovation. Organization Studies, 37(2), 131-159. https://doi.org/10.1177/0170840615604501 
Eisenhardt, K. (1989). Agency theory: An assessment and review. Academy of Management Review, 14(1), 57-74. https://doi.org/10.2307/258191

Elerud-Tryde, A., \& Hooge, S. (2014). Beyond the generation of ideas: Virtual idea campaigns to spur creativity and innovation. Creativity and Innovation Management, 23(3), 290-302. https://doi.org/10.1111/caim.12066

Epstein, R., Kaminaka, K., Phan V., \& Uda, R. (2013). How is creativity best managed? Some empirical and theoretical guidelines. Creativity and Innovation Management, 22(4), 359-374. https://doi.org/10.1111/caim.12042

Fairhurst, G. T. (2009). Considering context in discursive leadership research. Human Relations, 62(11), 1607-1633. https://doi.org/10.1177/0018726709346379

Giddens, A. (1984). The constitution of society: Outline of the theory of structuration. Berkeley and Los Angeles, EUA: University of California Press.

Gumusluoglu, L., \& Ilsev, A. (2009). Transformational leadership, creativity, and organizational innovation. Journal of Business Research, 62(4), 461-473. https://doi.org/10.1016/j.jbusres.2007.07.032

Harrison, S. H., \& Rouse, E. D. (2015). An inductive study of feedback interactions over the course of creative projects. Academy of Management Journal, 58(2), 375-404. https://doi.org/10.5465/amj.2012.0737

Harvey, S., \& Kou, C. (2013). Collective engagement in creative tasks: The role of evaluation in the creative process in groups. Administrative Science Quarterly, 58(3), 346-386. https://doi.org/10.1177/0001839213498591

Héraud, J. A. (2016). A new approach of innovation: From the knowledge economy to the theory of creativity applied to territorial development [online publication]. Journal of the Knowledge Economy, 1-17. https://doi.org/10.1007/s13132-016-0393-5

Mainemelis, C. (2010). Stealing fire: Creative deviance in the evolution of new ideas. Academy of Management Review, 35(4), 558-578. https://doi.org/10.5465/AMR.2010.53502801

Martin, J. (1992). Culture in organizations: Three perspectives. New York, EUA: Oxford University Press.

Mietzner, D., \& Kamprath, M. (2013). A competence portfolio for professionals in the creative industries. Creativity and Innovation Management, 22(3), 280-294. https://doi.org/10.1111/caim.12026

Montanari, F., Scapolan, A., \& Gianecchini, M. (2016). 'Absolutely free'? The role of relational work in sustaining artistic innovation. Organization Studies, 37(6), 797-821. https://doi.org/10.1177/0170840616647419

Muzzio, H. (2017). Indivíduo, liderança e cultura: Evidências de uma gestão da criatividade. Revista de Administração Contemporânea, 21(1), 107-124. Recuperado de http://www.scielo.br/pdf/rac/v21n1/1415-6555-rac-21-01-00107.pdf. https://doi.org/10.1590/1982-7849rac2017160039

Naranjo-Valencia, J. C., \& Calderón-Hernández, G. (2015). Construyendo una cultura de innovación: Una propuesta de transformación cultural. Estudios Gerenciales, 31(135), 223-236. https://doi.org/10.1016/j.estger.2014.12.005

Nonaka, I., \& Takeuchi, H. (1995). The knowledge-creating company. New York, EUA: Oxford University Press. 
Parjanen, S. (2012). Experiencing creativity in the organization: From individual creativity to collective creativity. Interdisciplinary Journal of Information, Knowledge, and Management, 7(1), 109128. https://doi.org/10.28945/1580

Patriotta, G., \& Hirsch, P. M. (2016). Mainstreaming innovation in art worlds: Cooperative links, conventions and amphibious artists. Organization Studies, 37(6), 867-887. https://doi.org/10.1177/0170840615622062

Perry-Smith, J. E. (2006). Social yet creative: The role of social relationship in facilitating individual creativity. Academy of Management Journal, 49(1), 85-101. https://doi.org/10.5465/AMJ.2006.20785503

Perry-Smith, J. E., \& Shalley, C. E. (2003). The social side of creativity: A static and dynamic social network perspective. Academy of Management Review, 28(1), 69-106. https://doi.org/10.5465/AMR.2003.8925236

Rickards, T., \& Moger, S. (2000). Creative leadership process in project team development: An alternative to Tuckman's stage models. British Journal of Management, 11(4), 273-283. https://doi.org/10.1111/1467-8551.00173

Rickards, T., \& Moger, S. (2006). Creative leaders: A decade of contributions from Creativity and Innovation Management Journal. Creativity and Innovation Management, 15(1), 4-18. https://doi.org/10.1111/j.1467-8691.2006.00365.x

Smircich, L. (1983). Concepts of culture and organizational analysis. Administrative Science Quarterly, 28(3), 339-358. https://doi.org/10.2307/2392246

Smith, W. K., \& Lewis, M. W. (2011). Toward a theory of paradox: A dynamic equilibrium model of organizing. Academy of Management Review, 36(2), 381-403. https://doi.org/10.5465/AMR.2011.59330958

Sohmen, V. S. (2015). Reflections on creative leadership. International Journal of Global Business, 8(1), 1-14. https://doi.org/10.13140/RG.2.1.1620.3366

Vissers, G., \& Dankbaar, B. (2002). Creativity in multidisciplinary new product development teams. Creativity and Innovation Management, 11(1), 31-42. https://doi.org/10.1111/1467-8691.00234

Whetten, D. A. (1989). What constitutes a theoretical contribution? Academy of Management Review, 14(4), 490-495. https://doi.org/10.5465/AMR.1989.4308371

\title{
Author
}

\author{
Henrique Muzzio \\ Rua dos Funcionários, s/n, Cidade Universitária, 50740-580, Recife, PE, Brasil. \\ E-mail: henrique.muzzio@ufpe.br \\ Fernando Gomes Paiva Júnior \\ Rua dos Funcionários, s/n, Cidade Universitária, 50740-580, Recife, PE, Brasil. \\ E-mail: fernando.paivajr@gmail.com
}

